\title{
Dry eye syndrome in reproductive age group women on oral contraceptives
}

\author{
Manoj Tyagi $^{1}$, Praveen Khare ${ }^{2, *}$, Amita Sharma ${ }^{3}$ \\ ${ }^{1,3}$ Assistant Professor, ${ }^{2}$ Associate Professor, Dept. of Ophthalmology, Bundelkhand Medical College Sagar, Madhya Pradesh, \\ ${ }^{3}$ Gandhi Medical College, Bhopal, Madhya Pradesh, India
}

*Corresponding Author:

Email: praveenkhare_77@ rediffmail.com

\begin{abstract}
Purpose: To investigate the correlation between dry eye syndrome with Androgen profile and its relation with use of Oral Contraceptives in females within child bearing age.

Materials and Methods: Study consists of 100 healthy women between 20-49 years, out of which 50 were on OCPs (Oral contraception pills) and rest 50 as control group were not taking any hormonal contraceptives. Androgen profile was carried out by Enzyme Immuno Assay on blood samples which were collected during 6th to 8th day (Early follicular phase) of menstrual cycle. The tear secretion was measured by Schirmer's test. Qualitative parameter of tear film was measures by Tear Breakup time (TBUT). Statistical analysis was done to determine the correlation between tear film parameters and androgen profile and oral contraceptive use.

Results: Our result demonstrate that androgen profile (serum testosterone and DHEA levels) were decreased significantly $(\mathrm{P}<0.05)$ in women taking oral contraceptives as compared with age matched women who were not taking oral contraceptives. Schirmer's test and TBUT readings were significantly reduced in women taking oral contraceptives.

Conclusion: Our findings shows that androgen levels decrease in women taking oral contraceptives. These results support that androgen deficiency and oral contraceptives may be an important etiological factor in pathogenesis of dry eye syndrome in premenopausal women
\end{abstract}

Keywords: Androgen profile, Schirmer's test, Tear film breakup time, Dry eye syndrome, Oral contraceptives.

\section{Introduction}

Dry eye syndrome (DES or keratoconjunctivitis sicca) is a common multifactorial disease of the tears and the ocular surface that can significantly diminish visual function and quality of life. ${ }^{1}$ It is one of the leading causes of patient visits to ophthalmologists and optometrists in the United States and many parts of the world. Dry eye syndrome (DES) is traditionally considered the disease of old age and female sex and also related with the hormonal variation. ${ }^{3}$ Sex steroids hormones (Androgens, Progestin and Estrogens) have been identified in tear film and their levels correlated with serum level. ${ }^{4}$ Androgen, estrogen and progesterone receptors mRNAs were present in the epithelial cells of the lacrimal gland, meibomian gland, lid, palpebral and bulbar conjunctivae. ${ }^{5}$ Thus suggesting the influence of not only estrogen but also of androgen and other sex hormones in the pathophysiology of DES. Estogen is known to cause decrease in lipid production and size of sebaceous glands. ${ }^{6}$

Researchers have discovered that androgens exert a significant influence on the structural characteristics, functional attributes, and pathologic features of the lacrimal gland. One of the most striking effects of androgens is their impact on lacrimal tissue disease in Sjogren's syndrome. ${ }^{7}$ This syndrome is a complex autoimmune disorder that occurs almost exclusively in women and has a devastating influence on the lacrimal gland. Autoimmune squeal include profound lymphocytic accumulation in lacrimal tissue, marked alterations in the expression of cytokines, adhesion molecules, and apoptotic factors, immune-mediated dysfunction or destruction of acinar and ductal epithelial cells, a precipitous decrease in aqueous tear secretion, and severe dry eye. ${ }^{4}$ Dry eye syndrome would be more during altered sex hormonal status such as during pregnancy, use of hormonal contraceptives and postmenopause. Despite this widely held clinical perception that use of hormonal contraceptive may be associated with dry eye syndrome. There are few studies done to correlate this relationship. ${ }^{7-11}$

Androgen deficiency as a cause for dry eye syndrome in aging male. ${ }^{12}$ Androgen deficiency due to use of oral contraceptives in females can be a responsible factor for dry eye in child bearing age group women. ${ }^{13-14}$ Androgen excess conditions are treated with oral contaceptives. It was also suggested that oral contraceptive might decrease mucus production, increase foreign body sensation, reduce contact lens tolerance and increases the risk of dry eye in women using oral contraceptive. ${ }^{15,20}$

Since large numbers of reproductive age group women are taking OCP as method of contraception, they might be at the risk of dry eye syndrome. We tried to investigate the correlation between OCP, their androgen profile and dry eye in women taking oral contraceptives in child bearing age group.

\section{Materials and Methods}

The study was prospective case control study carried out in department of ophthalmology. The participant consist of 100 healthy women of child bearing age group within the age of 20 to $45 \mathrm{yrs}$. The participants were visiting the family planning clinic of 
Gynecology OPD. The 100 participants were equally divided into two groups. The test group consists of 50 females who were currently on oral contraceptives. The control group consists of 50 females who were not using any hormonal contraceptive. The control and case group were menstrual cycle and age matched. Informed consent was obtained from each participant and study was approved by ethical committee of the institute. Detailed history regarding gynecological history, systemic medication use and duration of hormonal contraceptive was taken from all subjects. Any ocular complain was taken. Detailed ocular examination was done in eye OPD to rule out any ocular surface and anterior segment abnormality.

Inclusion Criteria for Control Group: Women of age between $20-45$ yrs, not on hormonal contraceptives and were in follicular phase (5-6 day) of menstrual cycle.

Inclusion Criteria for Case Group: Women within age group of 20-45 yrs who were on oral contraceptive (Mala-D and Mala-N) at least since last one year and all were on follicular phase.

Exclusion Criteria: Pregnancy, menopausal and women underwent for oopherectomy. Women with history of systemic disease, chronic systemic medication. Ocular factors which were excluded from study are ocular surgery, contact lens use, chronic topical medication, laser treatment, chemical injury, blepheritis and any other obvious ocular disorder.

Hormonal Assay: plasma level of total testosterone and DHEA were measured by EIA using Erba Elisa Reader. For this blood samples were collected from all participants who were in their early follicular phase (56 day). Blood was collected in specimen tubes without anticoagulant tubes were left to stand for 1 hour at room temperature and centrifuged at $2500 \mathrm{rpm}$ in microcentrifuge. Serum was collected in new specimen tubes and also kept at $-20{ }^{\circ} \mathrm{C}$ for long term storage.
Schirmer's I: test was done to measure the total tear secretion. Schirmers strip (Whatman filter paper41) was gently put at the junction of middle and outer $2 / 3$ of lower lid taking care not to touch the cornea or eye lashes. Participants were asked to look up and blink normally or to close the eye whichever the participant feel comfortable. The strip was then removed $5 \mathrm{~min}$ after insertion. Three subsequent readings were taken with $10 \mathrm{~min}$ interval. The wet portion of strip from bent portion was measured in $\mathrm{mm}$. Average of three readings were taken value less than $10 \mathrm{~mm} /$ after $5 \mathrm{~min}$ was considered as dry eye.

TBUT- was measured after fluorescein dye is instilled in cul-de-sac and tear film is observed on slit lamp with cobalt blue light. Participants were refrained from blinking and the first dark spot or streak were noticed this discontinuous in fluorescein indicate break in the continuity in tear film. The time elapsing between complete blink and the appearance of first dark spot or streak was measured with stop cloak three successive measurements were taken and mean value was taken. TBUT reading < 10sec was considered as dry eye.

Statistical Analysis: The data was analyzed with SPSS software. The effect of oral contraceptives on tear secretion and tear film stability in control and case group were determined by using students unpaired $t$ test and the correlation between plasma androgen (testosterone and DHEA) and tear secretion and tear film stability was determined by pearson correlation. $\mathrm{P}$ value $<.05$ were taken as significant.

\section{Results}

Study consists of 50 controls and 50 cases (test group). Androgen profile of both groups is shown in table- 1 and table 2

Table 1: Serum Testosterone levels

\begin{tabular}{|l|c|c|c|c|c|c|}
\hline & $\begin{array}{c}\text { Group for } \\
\text { testosterone }\end{array}$ & $\mathbf{N}$ & $\begin{array}{c}\text { Mean } \\
(\mathbf{n g} / \mathbf{d l})\end{array}$ & $\begin{array}{c}\text { Std. } \\
\text { Deviation }\end{array}$ & t-value & p-value \\
\hline $\begin{array}{l}\text { Serum } \\
\text { Testosterone levels }\end{array}$ & Control & 50 & 0.665 & 0.042 & 7.017 & 0.00 \\
\cline { 2 - 7 } & Case & 50 & 0.585 & 0.069 & & \\
\hline
\end{tabular}

Table 1 Mean serum testosterone was significantly reduced in test group as compared with control group and difference was statistically significant.

Table 2: Serum DHEA levels:

\begin{tabular}{|l|c|c|c|c|c|c|}
\hline & $\begin{array}{c}\text { Group for } \\
\text { DHEA }\end{array}$ & $\mathbf{N}$ & $\begin{array}{c}\text { Mean } \\
(\mathbf{m c g} / \mathbf{d l})\end{array}$ & $\begin{array}{c}\text { Std. } \\
\text { Deviation }\end{array}$ & t-value & p-value \\
\hline \multirow{2}{*}{$\begin{array}{l}\text { Serum DHEA } \\
\text { levels }\end{array}$} & Control & 50 & 9.854 & 0.778 & 8.546 & 0.00 \\
\cline { 2 - 7 } & Test & 50 & 8.624 & 0.657 & & \\
\hline
\end{tabular}

Table 2 Demonstrate mean serum levels of DHEA in both groups. The mean serum DHEA levels were significantly reduced in test group as compared with control group and difference was statistically significant.

These findings suggest that the androgen profile (serum women who were on oral contraceptives. testosterone and DHEA) was significantly reduced in 
Table 3: Schirmer's test

\begin{tabular}{|l|c|c|c|c|c|c|}
\hline & $\begin{array}{c}\text { Group for } \\
\text { Schirrmer's test }\end{array}$ & $\mathbf{N}$ & $\begin{array}{c}\text { Mean } \\
(\mathbf{m m} / \mathbf{5 m i n})\end{array}$ & $\begin{array}{c}\text { Std. } \\
\text { Deviation }\end{array}$ & t value & p value \\
\hline $\begin{array}{l}\text { Schirmer's } \\
\text { Test }\end{array}$ & Control & 50 & 31 & 7 & 16.1 & 0.00 \\
\cline { 2 - 7 } & Test & 50 & 13 & 3 & & \\
\hline
\end{tabular}

Table 3 Demonstrate the tear secretion (Schirmer's Test) in both groups. The mean of schirmer's test was significantly reduced in test group as compared with control group and difference was statistically significant.

These findings suggest that tear secretion was contraceptives. significantly reduced in women who were on oral

Table 4: TBUT test

\begin{tabular}{|c|c|c|c|c|c|c|}
\hline & Group for TBUT & $\mathbf{N}$ & $\begin{array}{c}\text { Mean } \\
(\mathbf{s e c})\end{array}$ & Std. Deviation & t value & p value \\
\hline \multirow{2}{*}{ TBUT } & Control & 50 & 13.6 & 1.4 & 0.9 & 0.35 \\
\cline { 2 - 7 } & Test & 50 & 11.9 & 1.3 & & \\
\hline
\end{tabular}

Table 4 Demonstrate mean TBUT test in both groups. The mean of TBUT test was not significantly reduced in test group as compared with control group.

Graph 1: Shows linear relationship between Schirmer's test and Serum DHEA concentration

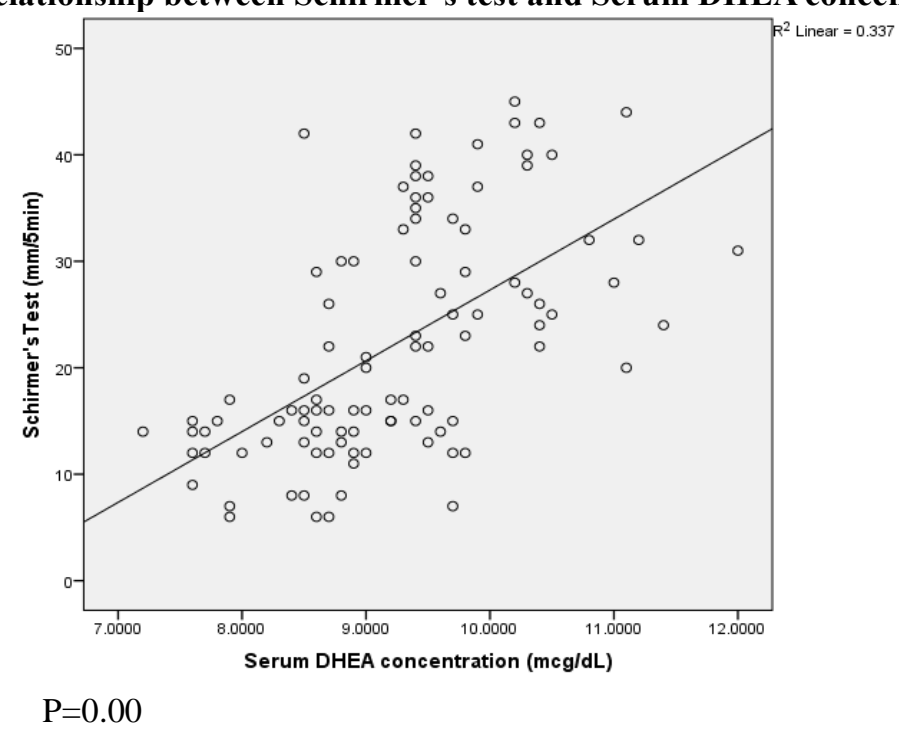

Graph 2: Linear relation between TBUT - test and Serum DHEA concentration

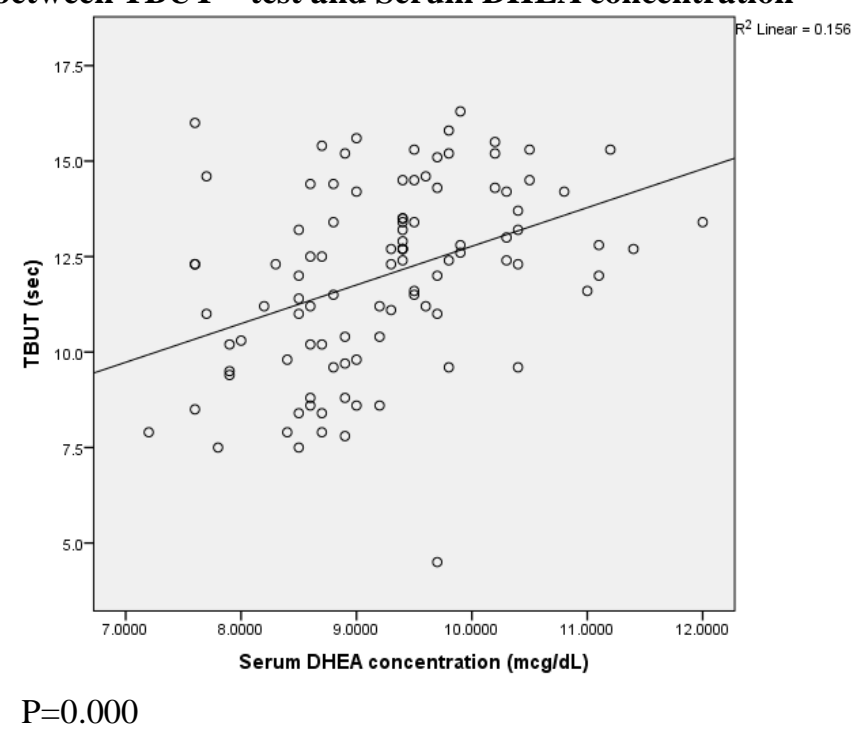

$\mathrm{P}=0.000$ 


\section{Graph 3: Shows linear relation between schirmer's test and serum Testosterone}

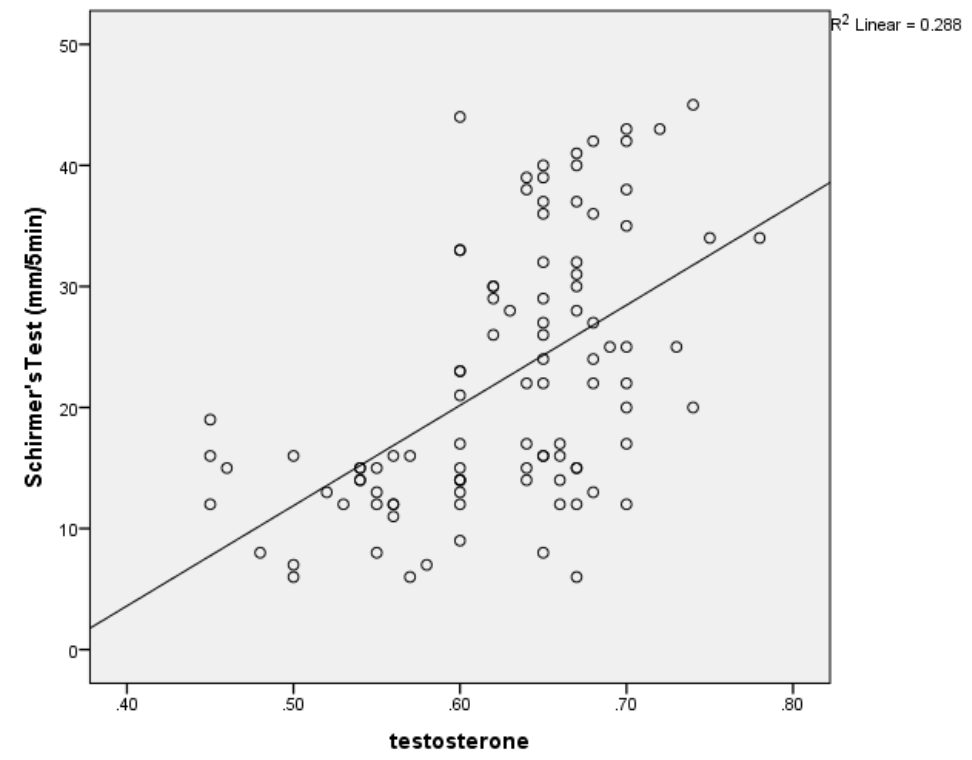

$\mathrm{P}=0.000$

Graph 4: Shows linear relation between TBUTs and serum Testosterone

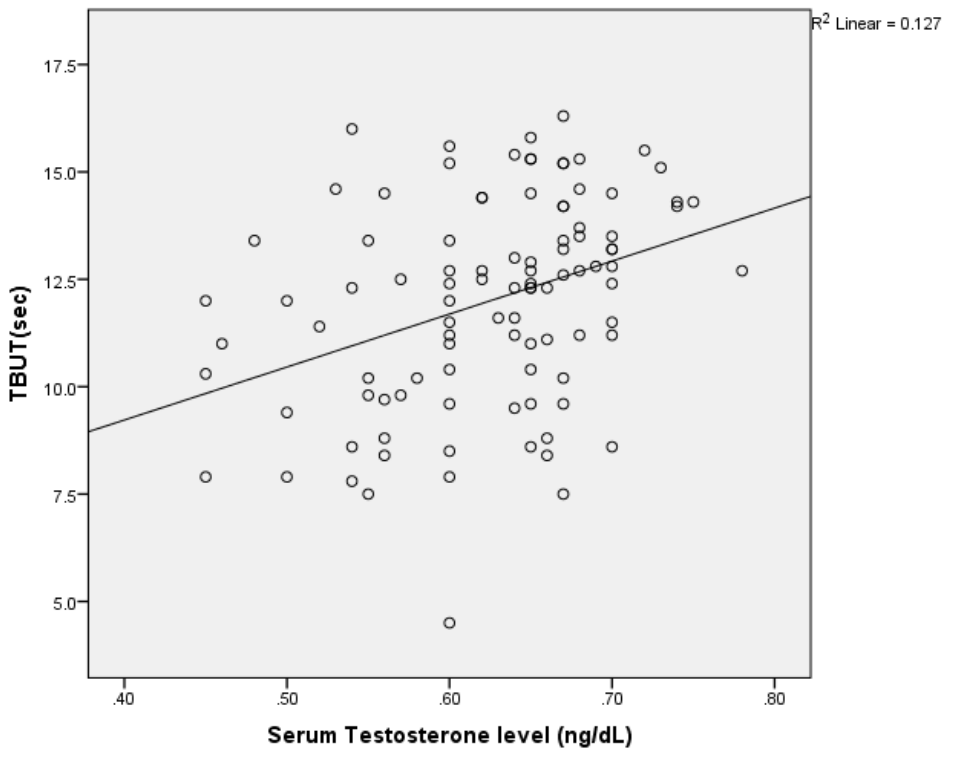

$\mathrm{P}=0.000$

\section{Discussion}

Dry eye is a generic term for a group of conditions characterized symptomatically by irritated, gritty, burning eyes and clinically by alteration in the tear film and anterior surface of the eye. ${ }^{1}$ Sex hormones appear to influence structural and functional aspects of the eye and contribute to ocular surface disorders such as DED. $^{2,4,17}$ In a normal menstrual cycle, the follicular phase (day 1-14) is marked by low levels of progesterone and levels of estrogen rises gradually, ovulation occurs mid-cycle (day 13-16) after the estrogen peak, and the luteal phase is marked by rising progesterone levels and less steep rise in estrogen levels. Hormonal contraceptives, most commonly combined synthetic estrogen and progesterone, work by inhibiting ovulation. ${ }^{16}$ Tear is a fluid that covers the cornea and the conjunctiva. Tears lubricate, nourish and protect the eyes from dust, irritants and infections. The primary role of the tear film is to establish a refractive surface of high quality for the cornea and to ensure the well-being of the corneal and conjuctival epithelium. The imbalances in the composition of tears, may either decrease tear production or encourage excessive tear evaporation. ${ }^{1}$

There are limited studies which evaluate changes in tear film in womens on oral contraceptives. ${ }^{11-14}$ The results of our study revealed that there were significant 
difference in tear secretion $(\mathrm{P}<0.05)$ and tear stability between women on oral contraceptives and women not using hormonal contraceptives. The results were consistent with the observation of J. Winokur et al who carried out a similar study on the correlation in androgen profile in pre-menopausal women with dry eye syndrome. ${ }^{14}$ They reported that the oral contraceptives in pre-menopausal women may contribute to dry eye syndrome. They also inferred that oral contraceptives may be an important cause of androgen deficiency in this age group. Faustina kemdinum et al. observed that there was no significant correlation between serum levels of progesterone level and tear secretion and tear film stability. ${ }^{9}$ They also did not found any correlation between tear film stability, secretion and use of injectable hormonal contraceptives in child bearing age. In this study they investigate the effect of injectable progesterone hormonal contraceptive on tear secretion and tear stability.

Similar results were observed by Tomlison et al. who carried out the study on the effect oral contraceptive on tear physiology, they reported no effect on normal tear physiology. ${ }^{8}$ A study by Patric MA et al found a weak correlation ship between low androgen levels and dry eye syndrome in male population. ${ }^{12}$ Similar results in old male population were reported by Galor A et al. ${ }^{3}$ In study by Sarah P. Chen et al SANDE scores were significantly higher in subjects who were on oral contraceptives than women who were not on OCP but OSDI was normal in both groups. ${ }^{11}$

Androgen profile is also decreased significantly in women in study group as compared to control group in our study. Similar finding were obtained in study by Y. Zimmerman et al and J Winokur et al. ${ }^{13,14}$ Recent study regarding management of dry by use of transdermal patch of testosterone suggest that deficiency of testosterone can be a risk factor in pathogenesis of dry eye syndrome. ${ }^{18,19}$

\section{Conclusion}

Our study suggests that androgen levels decrease in women taking oral contraceptives. These results support that androgen deficiency and oral contraceptives may be an important etiological factor in pathogenesis of dry eye syndrome. We did not include in our study the women in reproductive age group who were on only progesterone therapy. So this study could not identify effect of oestrogen or progesterone on dry eye individually. Further large trial needs to identify the hormonal effect on dry eye.

\section{References}

1. The definition and classification of dry eye disease: report of the Definition and Classification Subcommittee of the International Dry Eye Work Shop (2007). Ocul Surf. 2007;5:75-92.

2. Scaumberg DA, Sullivan DA, Dana MR. Epidemiology of dry eye Syndrome. Adv Exp Med Biol. 2002;506:989-
998.

3. Galor A, Feuer W, LeeDJ, Florez H, Venincasa VD, Perez VL. Ocular surface parameters in older male veterans. Invest Ophthalmol Vis Sci. 2013;54:1426-1433.

4. Sullivan DA. Tearful relationships? Sex, hormones, the lacrimal gland, and aqueous-deficient dry eye. Ocul Surf. 2004; 2(2):92-123.

5. Rocha EM, Wickham LA, da Silveira LA, et al. Identification of androgen receptor protein and 5 areductase mRNA in human ocular tissues. $\mathrm{Br} \mathrm{J}$ Ophthalmol. 2000;84:76-84.

6. Sullivan DA, Yamagami H, Lui M, et al. Sex steroids, the meibomian gland and evaporative dry eye. Adv Exp Med Biol. 2002;506:389-399.

7. Sullivan DA, Sullivan BD, Evan JE, et al. Androgen deficiency, meibomian gland dysfunction, and evaporative dry eye. Ann N Y Acad Sci.2002;966:211-22.

8. Tomlinson A, Pearce EI, Simmons PA, et al. Effect of oral contraceptives on tear physiology. Ophthalmic Physiol Opt.2001;219(1):9-16.

9. Faustina Kemdinum Idu, Michael Osita Emina, Christy Oyem Ubaru. Tear secretion and tear stability of women on hormonal contraceptives. Journal of Optometry. 2013;6:45-50.

10. Versura P, Fresina M, Campos EC. Ocular surface changes over the menstrual cycle in women with and without dry eye. Gynecol Endocrinol. 2007;23(7):385390.26.

11. Sarah P. Chen, Giacomina Massaro-Giordano, Maxwell Pistilli,et al. Tear osmolarity and dry eye symptoms in women using oral contraception and contact lenses. Cornea. 2013;32(4):423-428.

12. Azcarate PM, Venincasa VD, Feuer W, Stanczyk F, Schally AV, Galor A. Androgen deficiency and dry eye syndrome in the aging male. Invest Ophthalmol Vis Sci. 2014;55:5046-5053.

13. Y. Zimmerman, M.J.C. Eijkemans, H.J.T. Coelingh Bennink et al. The effect of combined oral contraception on testosterone levels in healthy women: A systemic review and metaanalysis. Human Reproduction Update. 2014;20:76-105.

14. J Winokur, R. Kapoor, S. Jain. Androgen profile in premenopausal women with dry eye syndrome. Investigative Ophthal and visual Science. 2008;49(13):5285.

15. Sullivan BD, Whitmer D, Nichols KK, et al. An objective approach to dry eye disease severity. Invest Ophthalmol Vis Sci. 2010;51(12):6125-6130.

16. Rivera R, Yacobson I, Grimes D. The mechanism of action of hormonal contraceptives and intrauterine contraceptive devices. Am J Obstet Gynecol. 1999; 181(5 Pt 1):12631269. [PubMed 10561657].

17. Ding J, Sullivan DA. Aging and dry eye disease. Exp Gerontol.2012;47:483-490.

18. Nanavaty MA, Long M, Malhotra R. Transdermal androgen patches in evaporate dry eye syndrome with androgen deficiency: A pilot study. Br J Ophthalmol. 2014;98:567-569.

19. Foulks GN, Nichols KK, Bron AJ, Holland EJ, McDonald $\mathrm{MB}$, Nelson JD. Improving awareness, identification, and management of meibomian gland dysfunction. Ophthalmology. 2012;119:S1-S12.

20. Seymenoglu G, Baser EF, Zerdeci N, et al. Corneal Biochemical properties during the menstrual cycle. Curr Eye Res. 2011;36(5):399-403. 